\title{
STATISTICAL ANALYSIS of EDUCATION QUALITY in SCHOOLS of TOMSK OBLAST by ASSESSING GRADES of GRADUATES from the 9th and 11th CLASSES
}

\author{
Yu.Ya. Katsman ${ }^{a}$, S.K. Temirbaev ${ }^{b}$ \\ National Research Tomsk Polytechnic University \\ Tomsk, Russia \\ akatsman@tpu.ru, ${ }^{\mathrm{b}}$ japandakz@gmail.com
}

\begin{abstract}
The paper presents a statistical analysis of education quality of graduates from Tomsk Oblast schools on the basis of the Basic State Examination (BSE) in the Russian language and mathematics for the 9th grade and the corresponding grades for the Unified State Examination (USE) for the 11th grade. Using the analysis deliverables in concordance with suggested criteria, the rating of schools was proposed. The work also uses the methods of factor analysis to study the statistical significance of differences in the USE grades for pupils that stayed in current school or changed the school after the ninth class.
\end{abstract}

Keywords - Statistical analysis, knowledge monitoring, testing, scatter plot, sample characteristic, rank, median, factor.

\section{INTRODUCTION}

The paper presents the evaluation and analysis of achievements in education of graduates from Tomsk Oblast schools. To estimate the quality of education, the results of USE (Unified State Examination) in the Russian language and mathematics were used. The work also takes into the consideration the results of BSE (Basic State Examination) in the same subjects for corresponding graduates. The data for the analysis of the USE results for the 11th grade were obtained in 2015; the corresponding results of BSE for the 9th grade were collected in 2013 . Thus, the quality of the training of each graduate was characterized by four grades: so-called primary grades in each discipline. The initial data array was represented by a matrix with the size of $4861 \times 21$, each line corresponding to a specific school graduate, while rows represented different parameters: name of a Municipal Educational Institution (MEI), location, class, BSE2013rus, etc. In compliance with the requirements stated above, the data lacks the graduates that did not take an exam in any of the mentioned subjects.

\section{STATEMENT OF WORK}

On the basis of the collected statistical data, it is necessary to determine the school ratings. Work [1] has shown that the determination of the school ratings in accordance with the combination of grades that were measured in different scales is a rather complex problem. Obviously, the maximum primary grades of BSE and UFE are different; more importantly, the maximum grades vary even for different subjects. Papers [2, 3] have studied the influence of different context factors on the school ratings.

The initial school ratings were determined for all MEIs of the region, excluding the small schools and those schools with the number of graduates, who passed the exam, less than 4 (nonrepresentative sample). At the next stage of the study, the school ratings were determined depending on the MEI's location: regional center (Tomsk and Seversk), village schools, etc.

The next task completed in this work was the statistical study of a connection between the grades in the 9th and 11th classes for graduates, who continued the education in the same school, and for those pupils who continued studying in the 10 th and 11th classes at another school. It is also worthmentioning that the causes leading to the change of a schoolfamily, social, ethic and other-are out of the scope of this study.

All studies presented in this work were made with the use of various modules of STATISTICA V10 software.

\section{RESULTS AND DISCUSSION}

After excluding from the analysis of nonrepresentative data, the MEI (school) rating of Tomsk Oblast was determined for 129 schools in each of 4 grades: 1 . Russian language, 9 th class; 2. Mathematics, 9th class; 3. Russian language, 9th class; 4. Mathematics, 11th class. In Tables I and II below, 15 best schools are presented that are arranged in a descending order of the average grade for a corresponding discipline. 
TABLE I. Rating of Tomsk Oblast schools in the Russian language

\begin{tabular}{|l|l|l|}
\hline No. & \multicolumn{1}{|c|}{ Rus.lang. 2013 9th class } & \multicolumn{1}{|c|}{ Rus.lang. 2015 11th class } \\
\hline 1 & Non-state Educational Institution “Gymnasium “Tom” & $\begin{array}{l}\text { Municipal Autonomous Educational Institution (MAEI) Malinovka } \\
\text { Middle School of Tomsk District }\end{array}$ \\
\hline 2 & MAEI Malinovka Middle School of Tomsk District & MAEI Siberian Vocational School \\
\hline 3 & $\begin{array}{l}\text { Municipal Budgetary Educational Institution (MBEI) Pudovka } \\
\text { Middle School (9th class, Russian language) }\end{array}$ & MAEI Tomsk Gymnasium No. 55 \\
\hline 4 & MBEI Chernaya Rechka Middle School of Tomsk District & MAEI Gymnasium No. 24 \\
\hline 5 & MEI Asino Middle School No. 2 of Tomsk Oblast & MAEI Middle School No. 80 \\
\hline 6 & MAEI Tomsk Gymnasium No. 55 & MBEI Parabel Middle School \\
\hline 7 & MBEI Spasskaya Middle School of Tomsk District & Regional State Budgetary Educational Institution (RSBEI) Tomsk \\
\hline 8 & RSBEI Tomsk Physics and Technology Lyceum & MAEI Middle School No. 65 \\
\hline 9 & MBEI Seversk Gymnasium & MBEI Academical Lyceum \\
\hline 10 & MEI Lyceum No. 8 named after N. N. Rukavishnikov & MBEI Seversk Lyceum \\
\hline 11 & MBEI Kurlek Middle School of Tomsk District & MAEI Vocational School for Humanities \\
\hline 12 & MBEI Seversk Lyceum & Non-state Educational Institution “Gymnasium “Tom” \\
\hline 13 & MBEI Samus Lyceum & MBEI Russian Classical Gymnasium No. 2 \\
\hline 14 & MAEI Siberian Vocational School of Tomsk & MBEI Seversk Gymnasium \\
\hline 15 & MBEI Middle School No. 83 & \\
\hline
\end{tabular}

TABLE II. Rating of Tomsk Oblast schools in Mathematics

\begin{tabular}{|l|l|l|}
\hline No. & \multicolumn{1}{|c|}{ Mathematics 2013 9th class } & \multicolumn{1}{|c|}{ Mathematics 2015 11th class } \\
\hline 1 & MAEI Malinovka Middle School of Tomsk District & RSBEI Tomsk Physics and Technology Lyceum \\
\hline 2 & MBEI Middle School No. 80 & MAEI Tomsk Gymnasium No. 55 \\
\hline 3 & RSBEI Tomsk Physics and Technology Lyceum & MAEI Spasskaya Middle School of Tomsk District \\
\hline 4 & MBEI Spasskaya Middle School of Tomsk District & MAEI Middle School No. 80 \\
\hline 5 & MAEI Tomsk Gymnasium No. 55 & MBEI Middle School No. 49 \\
\hline 6 & MBEI Seversk Lyceum & MBEI Academical Lyceum \\
\hline 7 & Non-state Educational Institution “Gymnasium Tom” & MBEI Seversk Lyceum \\
\hline 8 & MBEI Seversk Gymnasium & MAEI Malinovka Middle School of Tomsk District \\
\hline 9 & MAEI Tomsk Middle School No. 35 & MAEI Gymnasium No. 29 \\
\hline 10 & MEI Lyceum No. 8 named after N. N. Rukavishnikov & MAEI Seversk Physics and Mathematics Lyceum \\
\hline 11 & MAEI Seversk Physics and Mathematics Lyceum & Non-state Educational Institution "Gymnasium "Tom” \\
\hline 12 & MAEI Vocational School for Humanities & MBEI Kozhevnikovo Middle School No. 1 \\
\hline 13 & MBEI Academical Lyceum & MBEI Middle School No. 51 \\
\hline 14 & MAEI Gymnasium No. 29 & MBEI Shegarka Middle School No. 1 \\
\hline 15 & MBEI Middle School No. 49 & MBEI Kurlek Middle School of Tomsk District \\
\hline
\end{tabular}

The analysis of the obtained results demonstrated that only 5 schools of 129 have stable rating for each grade taking no lower than 15th place (highlighted in Tables I and II).

At the next stage, the study of rating was carried out for schools located in different types of inhabited areas: in regional center (Tomsk and Seversk) and in villages. Similarly to previous studies, the rating was determined using 4 grades in schools, where minimal number of graduates was larger than three.

Among the schools of the regional center, four schools have demonstrated stable and high rating: MAEI Tomsk Gymnasium No. 55, RSBEI Tomsk Physics and Technology Lyceum, MBEI Seversk Lyceum and Non-state Educational Institution "Gymnasium "Tom".

The formation of the rating for village schools was impeded by specific difficulties; only two schools were present in all four lists: MAEI Malinovka Middle School of Tomsk District and MBEI Kozhevnikovo Middle School No. 1 .
The school rating does not include the leaders of highquality education that are well known not only in Tomsk Oblast, but also in the Russian Federation in general: Lyceum of TPU and TSU Lyceum. Such "discrimination" is explained by the fact that this rating was formed with the use of four grades of the 9th and 11th classes, while in the said MEIs, there are no 9 th classes.

When solving the problem of school rating formation, we believed that our sample is uniform. Now let us choose 2 groups (categories) in this sample: 0 - pupils remained in their schools after the 9th class; 1 - pupils who transferred to other schools. In this case, it is of particular interest to compare grades in different disciplines for BSE and USE for these groups and answer the question, whether the grades in different groups demonstrate (statistically) significant difference, or such difference can be explained by random fluctuations. For each grade and for each group, nonparametric hypotheses on grade distribution normality were tested. In Fig. 1, there is a histogram of distribution of grades and the results of statistical tests. 


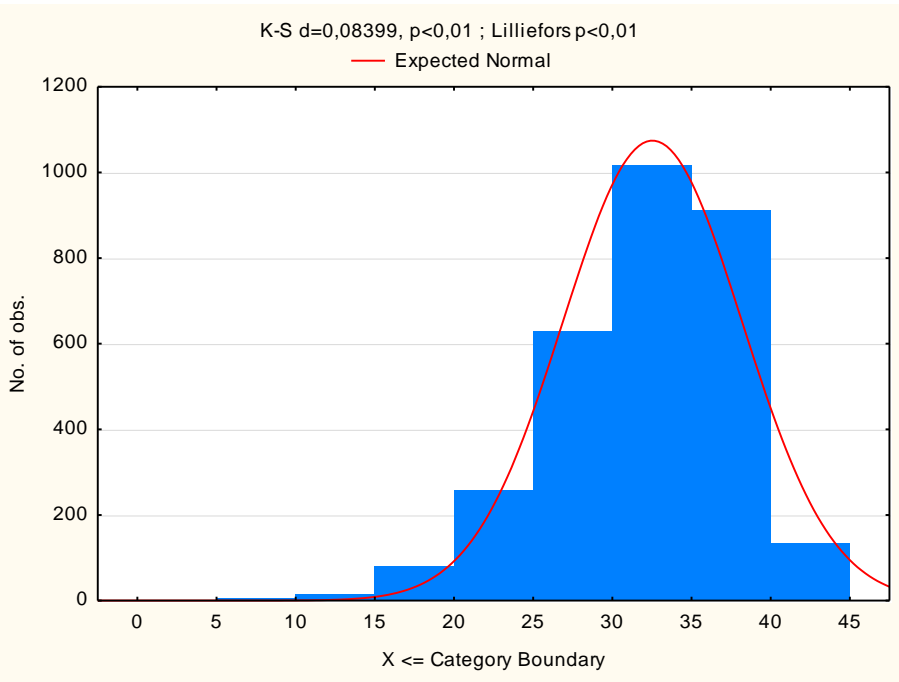

Fig. 1. Histogram of BSE grades in the Russian language for group 0

The comparison of empirical data and theoretical Gauss distribution (Fig. 1, solid line) has shown that the zero hypothesis (normal grade distribution) can be accepted with the probability of less than $1 \%$ with the significance level $\alpha$ $=0,05$. Thus, two independent criteria of KolmogorovSmirnov and Lilliefors testify the validity of the alternative hypothesis, according to which the distribution of grades is not a Gauss distribution. This derivation is valid for all studied grades, which makes the application of a number of tests inadequate for statistical analysis, for instance, t-test (Student's test). Let us continue the study with the help of rank criteria that do not depend on the type of distributions and usually have higher power as compared to parametric ones.

The test of zero hypothesis (grades/ranks of pupils from different groups are equal) will be carried out with the use of Kruskal-Wallis test. The results are presented in Table III.

TABLE III. Kruskal-Wallis test

\begin{tabular}{|c|c|c|c|c|}
\hline \multirow[t]{2}{*}{$\begin{array}{l}\text { Dependent: } \\
\text { BSE2013rus }\end{array}$} & \multicolumn{4}{|c|}{$\begin{array}{l}\text { Kruskal-Wallis ANOVA by Ranks; BSE2013rus } \\
\text { Independent (grouping) variable: } \\
\text { CategoryForTransition } \\
\text { Kruskal-Wallis test: } \\
\text { H }(\mathbf{1}, \mathrm{N}=\mathbf{3 5 8 1})=\mathbf{4 , 6 9 0 5 6 7} \quad \mathrm{p}=\mathbf{0 , 0 3 0 3}\end{array}$} \\
\hline & Code & Valid $N$ & Sum of Ranks & $\begin{array}{l}\text { Mean } \\
\text { Rank }\end{array}$ \\
\hline 0 & 0 & 3046 & 5407694,5 & 1775,343 \\
\hline 1 & 1 & 535 & 1005877 & 1880,143 \\
\hline
\end{tabular}

Let us briefly comment the obtained results. KruskalWallis statistics calculates the sum of squares of differences of middle ranks in a group and middle ranks of the whole sample. Then, if the hypothesis $H_{0}$ is valid, and the effect of the factor is negligible, the value of statistics is small, and the corresponding probability is large. In our case $H=4,680567$, so the zero hypothesis can be accepted with the probability of $p=0,0303$. Since this value is less than the significance level $(\alpha=0,05)$, the zero hypothesis should be rejected in favor of alternative hypothesis $H_{1}$, where the influence of the factor is considerable (the pupils' grades BSE2013rus for two groups are significantly different). Kruskal-Wallis test for 3 remaining grades has demonstrated the following: BSE2013math $-\mathrm{H}=35,47012$ $\mathrm{p}=0,0000$; USE2015rus $-\mathrm{H}=7,334785 \mathrm{p}=0,0068$; and USE2015math $-\mathrm{H}=55,64238 \mathrm{p}=0,0000$. Thus, for all four grades, the mean grades (ranks) for pupils who transferred to other school after the 9th class are much larger, than for pupils who remained in their schools.

Taking into account that different independent tests gave different sensitivity, the whole study was performed using the median test and Mann-Whitney $U$ test [4].

It is well known that the statistics of the median test for zero hypotheses asymptotically falls into line with the distribution $\chi^{2}$ with $k-1$ degrees of freedom. The made conclusions have confirmed the results of the previous test for all grades. The report on the MannWhitney $U$ test is presented in Table IV.

TABLE IV. Mann-Whitney test results

\begin{tabular}{|l|l|c|c|c|c|}
\hline \multirow{7}{*}{ Variable } & \multicolumn{5}{|c|}{ Mann-Whitney U test (Accuracy) By variable } \\
CategoryForTransition \\
\cline { 2 - 6 } & $\begin{array}{c}\text { Marked tests are significant at } \mathbf{p}<\mathbf{0 , 0 5 0 0 0} \\
\text { Rank Sum } \\
\text { Group 1 }\end{array}$ & $\begin{array}{c}\text { Rank } \\
\text { Sum } \\
\text { Group 2 }\end{array}$ & $U$ & $Z$ & $\begin{array}{c}p \text { - } \\
\text { value. }\end{array}$ \\
\hline USE2015rus.lang. & 5395695 & 1017876 & 755114 & $\mathbf{- 2 , 7 0 6}$ & $\mathbf{0 , 0 0 7}$ \\
\hline
\end{tabular}

\begin{tabular}{|c|c|c|c|c|}
\hline \multirow{2}{*}{ Variable } & \multicolumn{4}{|c|}{$\begin{array}{c}\text { Mann-Whitney U test (Accuracy) By variable } \\
\text { CategoryForTransition }\end{array}$} \\
\cline { 2 - 5 } & \multicolumn{3}{|c|}{ Marked tests are significant at p $\mathbf{0 , 0 5 0 0 0}$} \\
\cline { 2 - 5 } & Z adjusted & p-value & $\begin{array}{c}\text { Valid N } \\
\text { Group 1 }\end{array}$ & $\begin{array}{c}\text { Valid } N \\
\text { Group 2 }\end{array}$ \\
\hline USE2015rus.lang. & $\mathbf{- 2 , 7 0 8}$ & $\mathbf{0 , 0 0 6 8}$ & 3046 & 535 \\
\hline
\end{tabular}

Legend: $\mathbf{U}$ - Mann-Whitney statistics; $\mathbf{Z}$ - normal approximation of Mann-Whitney statistics for large samples; p - probability of $H_{0}$ hypothesis acceptance; Zadjusted - adjusted normal large samples; $\mathbf{p}-$ probability of $H_{0}$ hypothesis acceptance; Zadjusted - adjusted normal
approximation of Mann-Whitney statistics; Group 1 - pupils of 0 category; Group 2 - pupils of 1 category.

Since the analysis of Mann-Whitney $U$ test for all grades coincided with the conclusions of previous criteria, the zero hypotheses should be rejected and the alternative one should be accepted, i.e. the grades of pupils transferred to other schools are significantly different from the grades of pupils who stayed in the same school.

Considering the fact that the rank criteria give only qualitative estimation of factor influence yields the quantitative grades in the frame of dispersion analysis [4, 5]. Table $\mathrm{V}$ gives the results of dispersion analysis. 
TABLE V. Results of dispersion analysis

\begin{tabular}{|c|c|c|c|c|}
\hline \multirow{2}{*}{ Variable } & \multicolumn{4}{|c|}{$\begin{array}{c}\text { Analysis of Variance (Accuracy) } \\
\text { Marked effects are significant at } p<0,05000\end{array}$} \\
\hline & $\begin{array}{c}S S \\
\text { Effect }\end{array}$ & $\begin{array}{c}d f \\
\text { Effect }\end{array}$ & $\begin{array}{c}\text { MS } \\
\text { Effect }\end{array}$ & $\begin{array}{c}S S \\
\text { Error }\end{array}$ \\
\hline USE2015rus.lang. & 380,221 & 1 & 380,221 & 253438,6 \\
\hline USE2015math & 2832,512 & 1 & 2832,512 & 75970,4 \\
\hline
\end{tabular}

\begin{tabular}{|l|c|c|c|c|}
\hline \multirow{3}{*}{ Variable } & \multicolumn{4}{|c|}{$\begin{array}{c}\text { Analysis of Variance (Accuracy) } \\
\text { Marked effects are significant at p < 05000 }\end{array}$} \\
\cline { 2 - 5 } & $\begin{array}{c}d f \\
\text { Error }\end{array}$ & $\begin{array}{c}\text { Error } \\
\text { Error }\end{array}$ & $\boldsymbol{F}$ & $\boldsymbol{p}$ \\
\hline USE2015rus.lang. & $\mathbf{3 5 7 9}$ & $\mathbf{7 0 , 8 1 2 6 8}$ & $\mathbf{5 , 3 6 9 4}$ & $\mathbf{0 , 0 2 0 5 4 9}$ \\
\hline USE2015math & $\mathbf{3 5 7 9}$ & $\mathbf{2 1 , 2 2 6 7 1}$ & $\mathbf{1 3 3 , 4 4 0 9}$ & $\mathbf{0 , 0 0 0 0 0 0}$ \\
\hline
\end{tabular}

Legend: SS (Sum of Squares) Effect - sum of squares of factors (second estimation of dispersion) multiplied by $k-1$; df Effect - number of degrees of freedom of the factor; MS (Mean Square) Effect - mean square of the factor; SS Error - sum of square (estimate of dispersion) multiplied by $N-k$; df Error - number of degrees of freedom of observations equal to $N-k$; MS Error by $N-k$; df Error - number of degrees of freedom of observations equal to $N-k$; MS
estimate of dispersion; $\mathbf{F}-$ Fischer's statistics; $\mathbf{p}$ - probability of $H_{0}$ hypothesis acceptance.

Table $\mathrm{V}$ gives the grades for the 11th class, while for the grades in the Russian language, the Fisher's statistics $F$ negligibly differs from 1 with the probability of $\sim 2 \%$; for mathematics, this probability is $\sim 0$, which in the worst case is appreciably less than the level of significance. The illustrative representation of the influence of the factor is given in Fig. 2.

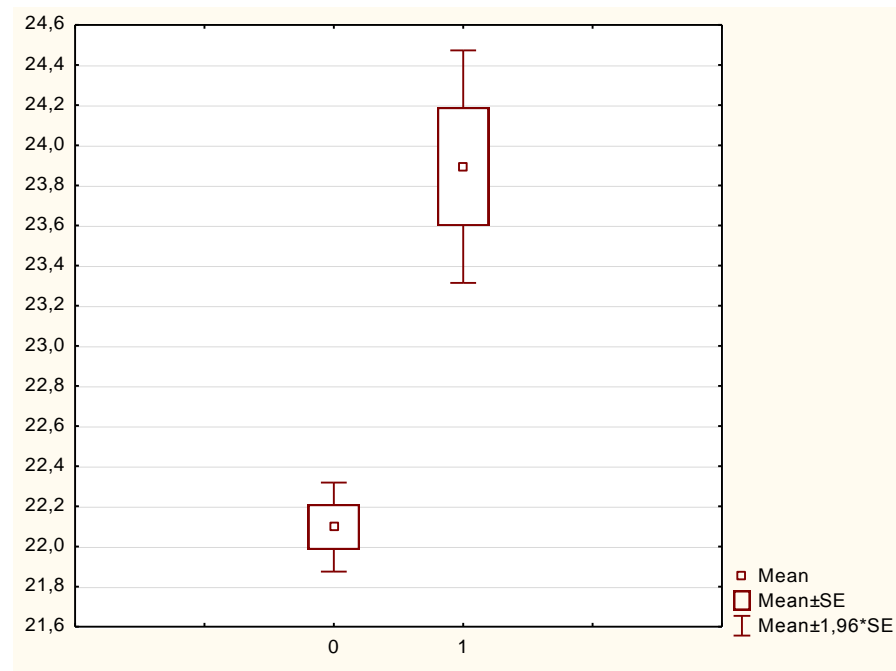

Fig. 2. Scatterplot for BSE2013math. (two categories)

\section{CONCLUSIONS}

The formation of the ratings of schools of Tomsk Oblast using four grades (BSE and USE) allowed discovering the following fact: from 5 best schools (that deliver high-quality education) one is located in the countryside (MAEI Malinovka Middle School of Tomsk District, one is in Seversk (MBEI Seversk Lyceum) and three of them are in the regional center, Tomsk (MAEI Tomsk Gymnasium No. 55, RSBEI Tomsk Physics and Technology Lyceum and Non-state Educational Institution "Gymnasium “Tom”).

The evaluation of the influence of the factor (category) on the grades of BSE and USE testify that they are significantly different. The grades for BSE of pupils who stayed in the 9th class of the same school are lower than the grades of those who transferred to other schools; such trend also persists for USE. It should be noted that the difference in grades in mathematics is appreciably larger than that for the Russian language.

\section{REFERENCES}

[1] Agranovich M.L. Can the results of USE and SFE be compared? Comparison of indicators calculated using different tests (in Russian) // Issues of education. - 2014. - No. 1. - P. 80-91.

[2] Katsman Yu.Ya., Lepustin A.V., Ilyukhin B.V. Influence of contex factors on the estimate of efficiency of schools in Tomsk Oblast [Electronic source] (in Russian) // Modern problems of science and education. - 2014. - No. 6. - P. 1-11. - Access: http://www.scienceeducation.ru/120-16117.

[3] Ilyukhin B.V., Katsman Yu.Ya. Risks in formation and application of ratings in the general education system of the Russian Federation (in Russian) // ratings in education: from single-use practices to cultural solutions: source book. - Moscow: Higher School of Economics. - 2014. - P. 140-146.

[4] Kobzar A.I. Applied mathematical statistics. For engineers and scientists. (in Russian) - Moscow: FIZMATLIT, 2006. - 816 p.

[5] Borovikov V. STATISTICA. The art of computer-aided data analysis: for professionals (in Russian). 2nd issue. - St. Petersburg: Piter, $2003-688$ p. 